\title{
Implementation of the FIFO Method in the Development of Inventory Applications for Agents Sinar Baru
}

\section{Implementasi Metode FIFO Dalam Pengembangan Aplikasi Persediaan Barang Pada Agen Sinar Baru}

\author{
Abdillah Fikri' ${ }^{1}$ Andika ${ }^{2}$, Mohamad Alfis Dava Cahyoga ${ }^{3}$, Anita Ratnasari ${ }^{4}$ \\ 1,2,3,4 Sistem Informasi, Universitas Mercu Buana, Jakarta, Indonesia \\ Email: 1abdillahfikri38@gmail.com, ${ }^{2}$ andikairawan167@gmail.com,3davayoga1@gmail.com, \\ 4anita.ratnasari@mercubuana.ac.id
}

\begin{abstract}
sinar baru adalah sebuah agen sembako yang berada di daerah kemanggisan kota Jakarta barat, sinar baru menjual berbagai sembako yang diperlukan dengan semakin banyaknya pembeli maka dari itu dibutuhkan suatu aplikasi yang mempermudah untuk pembelian atau pemesenan sembako tersebut, masalah yang terjadi adalah masih manualnya pencatatan persediaan barang pada agen yang mengakibatkan sering terjadinya kesalahan dalam pencatatan barang yang masuk dan keluar pada agen dan juga dalam hal pemesanan barang pelanggan diharuskan datang ke agen tersebut yang mengakibatkan memakan waktu yang tidak efektif. Aplikasi ini dibuat dengan menggunakan metode FIFO yakni barang yang pertama kali masuk atau datang akan terlebih dahulu dijual,UML digunakan untuk mendesain aplikasi dengan menggunakan Usecase Diagram, Activity Diagram, Sequence Diagram, Class Diagram, teknik pengumpulan data dilakukan dengan observasi dan wawancara, hasil dari penelitian ini adalah aplikasi dapat mengakses ketersediaan barang yang ada, laporan penjualan, laporan pembelian, laporan barang masuk, laporan barang keluar, laporan laba, laporan data pelanggan dan laporan stok barang.
\end{abstract}

Kata Kunci: sinar baru, Uml, FIFO

\section{PENDAHULUAN}

Perkembangan teknologi komputer saat ini sangat mempengaruhi di segala bidang, baik dibidang pendidikan, pemerintahan, pertahanan negara, bisnis, dan lain-lain[1]. Teknologi informasi merupakan sarana yang sangat penting dalam menjalankan suatu pekerjaan karena dengan teknologi informasi diharapkan dapat mempermudah pekerjaan dan dapat mencapai tujuan secara maksimal[2]. 


\section{JournalofInformation Systems andInformatics}

Vol. 2, No. 2, September 2020

p-ISSN: 2656-5935 http://journal-isi.org/index.php/is

e-ISSN: 2656-4882

Teknologi yang berkembang sekarang ini sangat berguna untuk membantu setiap orang dalam menyelesaikan masalah, hanya saja bagaimana caranya kita bisa menggunakan dan memanfaatkannya dengan baik sesuai kebutuhan kita[3].

Websitemerupakan salah satu media informasi yang sangat efektifdalam menyajikan informasi, dengan kemajuan teknologi yang semakin pesat serta permintaan akan kebutuhan yang semakin meningkat maka sangat perlu dibutuhkan sistem yang dapat membantu dalam pekerjaan dan juga dalam penyampaian informasi. Adanya jaringan yang luas dan mudah di akses juga merupakan salah satu langkah untuk mendapatkan informasi dengan cepat, maka setiap instansiingin mengubah sistem yang lama ke sistem yang baru agar tidak tertinggal dengan yang lain[4].

Setiap usaha yang didirikan baik kecil, menengah, ataupun besar pasti mempunyai suatu tujuan yang sama yaitu bagaimana caranya agar mendapatkan suatu keuntungan[5].Persediaan barang merupakan salah satu aktifitas perusahaan yang sangat penting bagi perkembangan perusahaan[6]. Persediaan barang dapat menyelesaikan masalah yang terkait dengan usaha pengendalian bahan baku maupun barang jadi dalam suatu aktifitas toko[7].

Agen sinar baru adalah sebuah toko yang bergerak dibidang distribusi barang yang menjual berbagai kebutuhan seperti makanan, minuman dan juga sembako. sistem persediaan barang pada toko ini masih menggunakan manual yakni masih dicatat didalam sebuah buku, sehingga toko sering mengalami kendala dalam pengelolaan barang. permasalahan dalam agen sinar baru ini adalah pengelolaan persediaan pada toko ini sebelumnya hanya melakukan proses manual. Yaitu mengalami suatu permasalahan di dalam mengelola persediaan dari transaksi penjualan dan pembelian, sehingga akan menyebabkan lambatnya pekerjaan yang dihasilkan. oleh karena itu kami menggunakan sebuah metode fifo yakni adalah barang yang pertama kali masuk berarti adalah barang yang pertama kali akan kami jual. tujuan dari penelitian ini adalah untuk mempermudah pegawai dalam mengelolah ketersediaannya stok barang yang ada dan juga agar tidak terjadinya penumpukan barang di gudang. 


\section{METODE PENELITIAN}

\subsection{Teknik Pengumpulan Data}

Teknik pengumpulan data dilakukan dengan menggunakan berbagai sumber informasi yang terdiri dari:

1. Observasi

Pada metode ini dilakukan penelitian langsung di Agen Sinar Baru. Penelitian ini dilakukan untuk mengetahui proses bisnis yang sedang berjalan.

2. Wawancara

Pada metode ini, pengumpulan data dengan penulisan melakukan wawancara dengan pihak pemilik Agen Sinar Baru.

3. Studi Pustaka

Metode ini dilakukan untuk mengumpulkan data dengan cara membaca berbagai macam artikel, dan jurnal yang berhubungan dengan sistem yang akan dibuat.

\subsection{Metode Agile}

Metode agile merupakan salah satu metode yang sering digunakan dalam proses pengembangan perangkat lunak. Tahap-tahapnya adalah sebagai berikut :

1. Requirement (perencanaan), dalam membangun sistem informasi agen sembako sinar baru berbasis web, dimana aplikasi ini melibatkan pemilik dan pembeli.

2. Design, membuat desain dengan menggunakan Unified Modelling Language dimana terdapat Use Case Diagram, Activity Diagram, Class Diagram, sequence diagram.

\subsection{Metode FIFO}

Metode FIFO merupakan metode dimana barang pertama yang masuk berarti barang tersebutlah yang pertama keluar. Menurut (Zulian,2005), "dengan metode FIFO, biaya persediaan dihitung berdasarkan asumsi bahwa barang akan dijual atau dipaki sendiri dan sisa dalam persediaan menunjukkan pembelian atau produksi yang terakhir'"[8].

\subsection{UML}

UML adalah bahasa pemodelan untuk sistem atau perangkat lunak yang berparadigma berorientasi objek. UML merupakan salah satu tool model untuk merancang pemodelan software yang berbasis object oriented[10]. 
Vol. 2, No. 2, September 2020

p-ISSN: 2656-5935 http://journal-isi.org/index.php/isi e-ISSN: 2656-4882

\subsection{Black Box}

Black-Box Testing merupakan Teknik pengujian perangkat lunak yang berfokus pada spesifikasi fungsional dari perangkat lunak[9].

\subsection{Diagram Alir Penelitian}

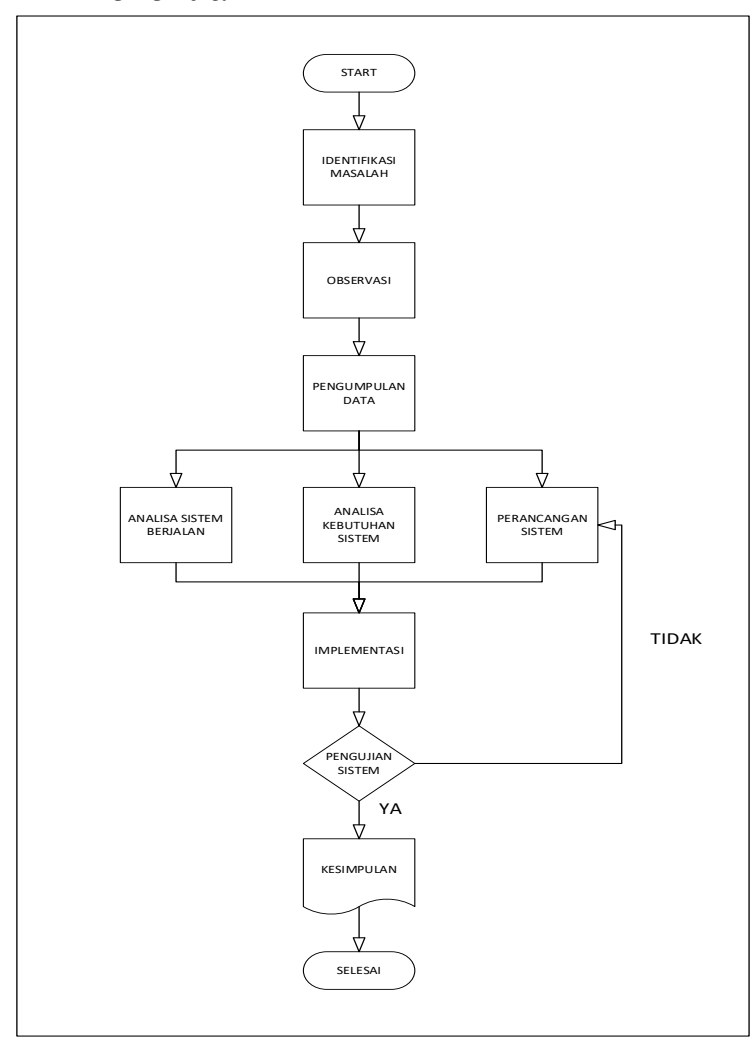

Gambar 1 Diagram Alir Penelitian

Penjelasan dari Diagram Alir Penelitian:

Berdasarkan diagram alir diatas dapat dijelaskan bahwa peneliti saat memulai penelitian melakukan identifikasi masalah yang ada pada agen sembako sinar baru terlebih dahulu dengan menggunakan analisa pieces agar mengetahui masalahmasalah yang ada. Tahap selanjutnya observasi peneliti melakukan wawancara, studi literature dan mengumpulkan data. Pada tahap selanjutnya peneliti melakukan analisa kebutuhan sistem, merancang sistem. Tahapan implementasi dimana sistem sudah di implementasikan, mempersilahkan pihak agen Sinar Baru untuk menguji sistem serta menganalisis lagi apakah sistem yang di uji sudah sesuai dengan kebutuhan atau belum jika belom sesuai peneliti akan kembali melakukan perancangan dimana memulai perancangan sistem dan memulai membuat aplikasi, jika sudah sesuai maka peneliti menarik kesimpulan dan penelitian pun selesai dilakukan. 
Vol. 2, No. 2, September 2020

p-ISSN: 2656-5935 http://journal-isi.org/index.php/isi

e-ISSN: 2656-4882

\section{HASIL DAN PEMBAHASAN}

\subsection{Analisa Proses Bisnis}

Berikut ini merupakan analisis proses bisnis pada sistem yang berjalan di agen sembako sinar baru dengan menggunakan rice picture diagram :

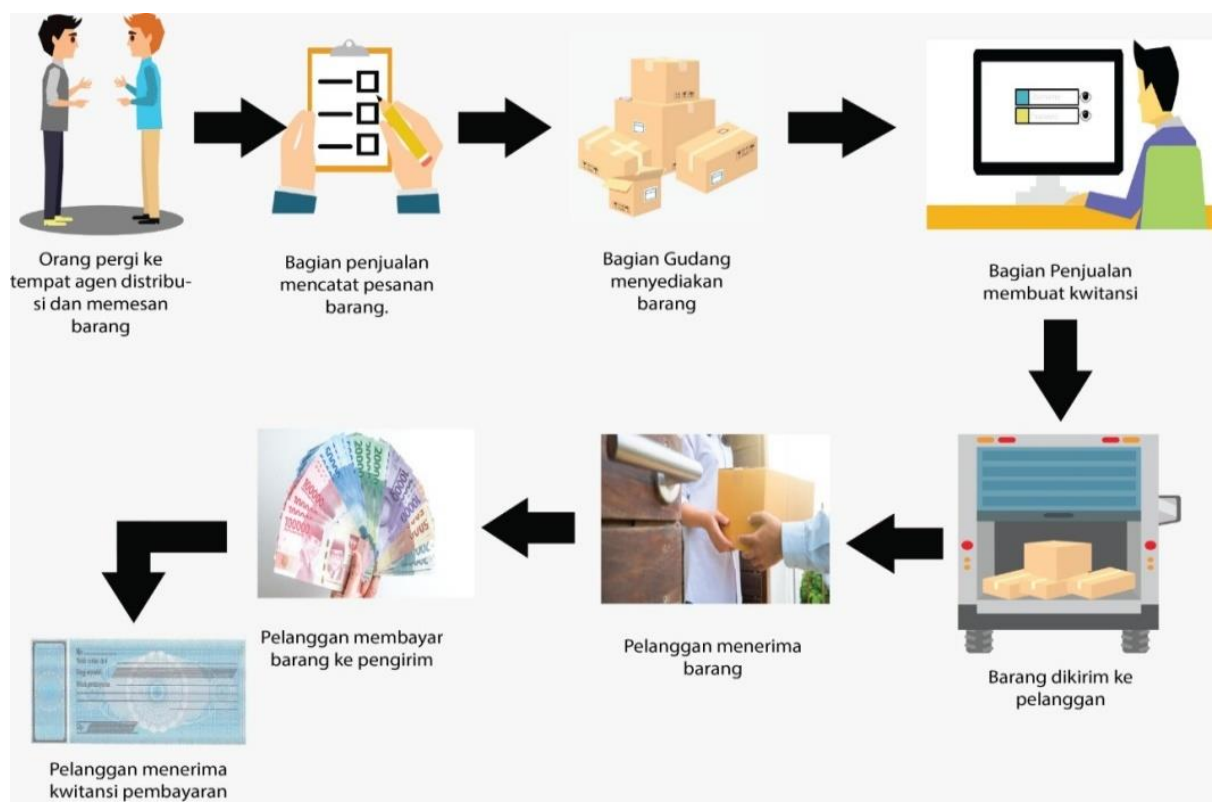

Gambar 2 Analisa Proses Bisnis

Penjelasan dari Analisa Proses Bisnis :

Pelanggan pergi tempat agen untuk melakukan pememesan barang, bagian penjualan mencatat pesanan barang, bagian gudang menyediakan barang, bagian penjualan membuat kwitansi, barang dikirim ke pelanggan, pelanggan menerima barang, pelanggan membayar barang, pelanggan menerima kwitansi pembayaran.

\subsection{Identifikasi Masalah}

Untuk mengidentifikasi permasalahan, penulis menggunakan metode analisa PIECES untuk mengidentifikasi kekuatan, kelemahan, peluang dan ancaman selama mengembangakan persediaan barang pada agen sembako Sinar Baru :

Tabel 1 Analisa PIECES

\begin{tabular}{|c|cc|c|}
\hline Kriteria & Masalah & \multicolumn{1}{c|}{ Solusi } \\
\hline $\begin{array}{c}\text { Performance } \\
\text { (Kinerja) }\end{array}$ & $\bullet$ & $\begin{array}{l}\text { Masih melakukan } \\
\text { manual dalam }\end{array}$ & $\bullet \begin{array}{l}\text { Data pada admin dapat langsung } \\
\text { menambahkan, menghapus barang } \\
\text { yang tersedia. }\end{array}$ \\
\hline
\end{tabular}


Vol. 2, No. 2, September 2020

p-ISSN: 2656-5935 http://journal-isi.org/index.php/isi e-ISSN: 2656-4882

\begin{tabular}{|c|c|c|}
\hline & $\begin{array}{l}\text { pencatatan data } \\
\text { barang dan } \\
\text { pencatatan } \\
\text { penjualan }\end{array}$ & $\begin{array}{l}\text { Data hasil tindak lanjut akan } \\
\text { diinputkan kedalam sistem untuk } \\
\text { mengetahui laporan barang keluar. } \\
\text { - Kinerja karyawan menjadi lebih } \\
\text { cepat, mudah, dan efisien. } \\
\text { Penyimpanan data menggunakan } \\
\text { database, sehingga apabila } \\
\text { kehilangan data berupa hardcopy, } \\
\text { pihak pemilik agen sinar baru } \\
\text { masih memiliki backup data yang } \\
\text { tersimpan di dalam database. }\end{array}$ \\
\hline $\begin{array}{l}\text { Information } \\
\text { (Informasi) }\end{array}$ & $\begin{array}{l}\text { - Informasi masih } \\
\text { menggunakan } \\
\text { manual. }\end{array}$ & $\begin{array}{l}\text { - Informasi dari data barang masuk } \\
\text { dan keluar sudah terkomputerisasi. }\end{array}$ \\
\hline $\begin{array}{l}\text { Economics } \\
\text { (Ekonomi) }\end{array}$ & $\begin{array}{l}\text { Masih menggunakan } \\
\text { pencatatan manual } \\
\text { dalam buku yang } \\
\text { mengharuskan } \\
\text { mengeluarkan dana } \\
\text { lebih banyak. } \\
\end{array}$ & $\begin{array}{l}\text { Adanya sebuah database } \\
\text { menjadikan pihak pemilik agen } \\
\text { sembako sinar baru menghemat } \\
\text { pengeluaran. }\end{array}$ \\
\hline $\begin{array}{l}\text { Control (control } \\
\text { atau keamanan) }\end{array}$ & $\begin{array}{l}\text { Data laporan barang } \\
\text { masuk dan keluar } \\
\text { dapat dimanipulasi } \\
\text { oleh karyawan } \\
\text { gudang karena } \\
\text { masih menggunakan } \\
\text { manual dalam } \\
\text { melakukan } \\
\text { pencatatan laporan. } \\
\end{array}$ & $\begin{array}{l}\text { Data laporan barang masuk dan } \\
\text { keluar tidak dapat dimanipulasi oleh } \\
\text { karyawan karena semua data telah } \\
\text { tersimpan didalam database yang } \\
\text { hanya dapat diakses oleh admin dan } \\
\text { pemilik. }\end{array}$ \\
\hline $\begin{array}{l}\text { Efficiency } \\
\text { (Efisiensi) }\end{array}$ & $\begin{array}{l}\text { Dari pencatatan } \\
\text { data, pemesanan } \\
\text { barang, membuat } \\
\text { laporan barang } \\
\text { keluar dan masuk } \\
\text { masih menggunakan } \\
\text { manual menjadi } \\
\text { kurang efisien } \\
\end{array}$ & $\begin{array}{l}\text { Adanya sistem yang dibuat dapat } \\
\text { membantu dalam hal } \\
\text { penyimpanan data, pemesanan } \\
\text { barang, membuat laporan barang } \\
\text { keluar dan dan masuk dapat } \\
\text { menjadi efisien. }\end{array}$ \\
\hline $\begin{array}{l}\text { Service } \\
\text { (Pelayanan) }\end{array}$ & $\begin{array}{l}\text { - Pelayanannya lama } \\
\text { karena masih harus } \\
\text { langsung } \\
\text { mengunjungi tempat } \\
\text { tersebut dalam } \\
\text { pemesanan barang. }\end{array}$ & $\begin{array}{l}\text { Tidak membutuhkan waktu yang } \\
\text { lama dalam hal pemesanan } \\
\text { barang karena sudah bisa } \\
\text { melakukan pemesanan barang } \\
\text { secara online. }\end{array}$ \\
\hline
\end{tabular}




\section{JournalofInformation Systems andInformatics}

Vol. 2, No. 2, September 2020

p-ISSN: 2656-5935 http://journal-isi.org/index.php/isi

e-ISSN: 2656-4882

\subsection{Use Case}

Use case adalah suatu pola atau gambaran yang menunjukan kelakukan atau kebiasaan sistem[11].

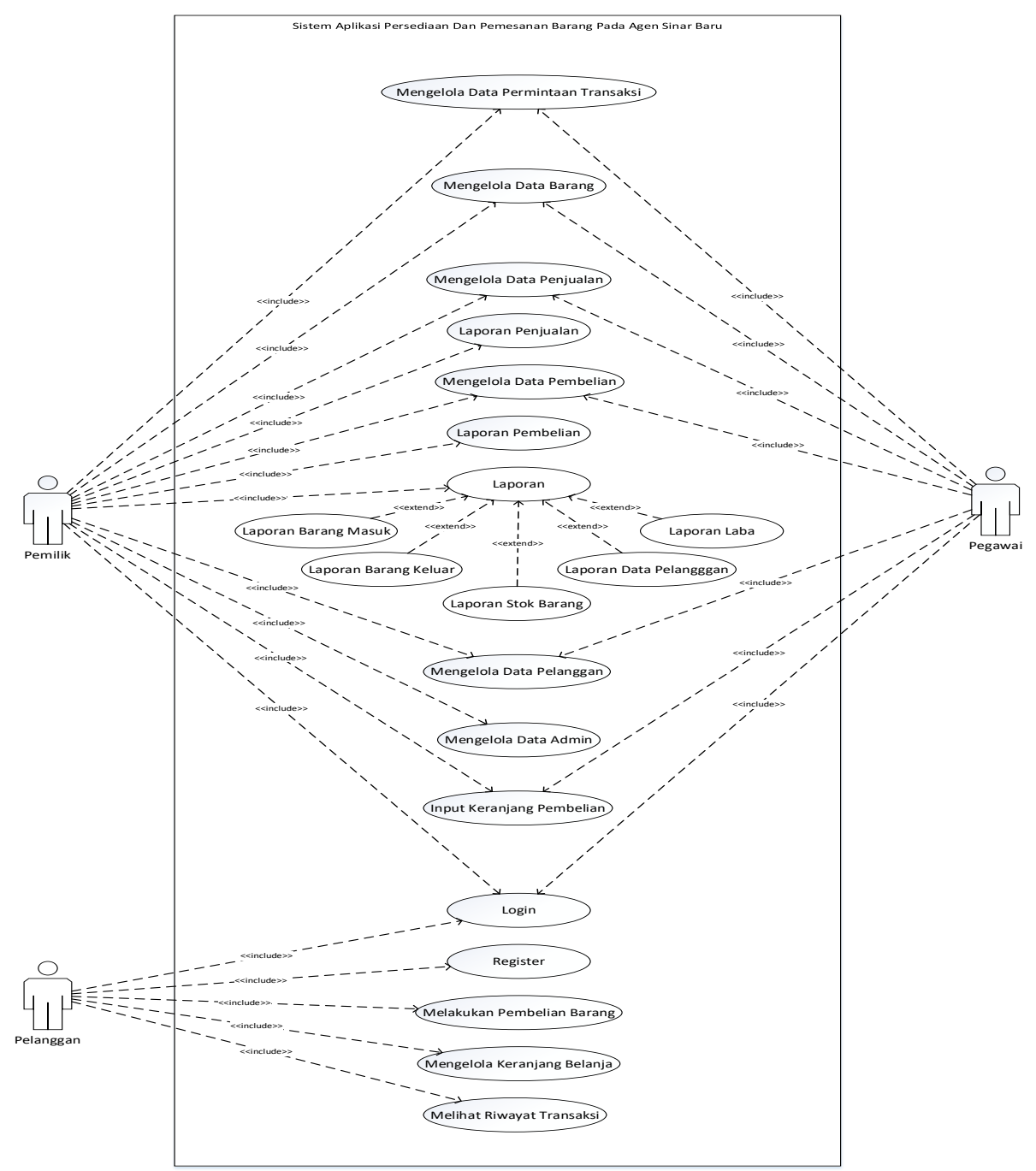

Gambar 3. Diagram Use Case

Pada use case diatas penjelasan pendifisian actor use case:

1. pemilik

pemilik dapat login, mengelola data barang, mengelola data penjual, mengelola data pembelian, laporan penjualan, laporan pembelian, mengelola data pelaggan, mengelola data pegawai, input keranjang pembelian.

2. pegawai 


\section{JournalofInformation Systems andInformatics}

Vol. 2, No. 2, September 2020

p-ISSN: 2656-5935 http://journal-isi.org/index.php/isi

e-ISSN: 2656-4882

pemilik dapat login, mengelola data barang, mengelola data penjual, mengelola data pembelian, mengelola data pelaggan, mengelola data pegawai, input keranjang pembelian.

3. pelanggan

pelanggan melakukan registrasi, login, melakukan pemesanan barang, melihat pemesanan, melihat riwayat transaksi.

\subsection{Activty Diagram}

1. Activity Diagram Melihat Riwayat Transaksi

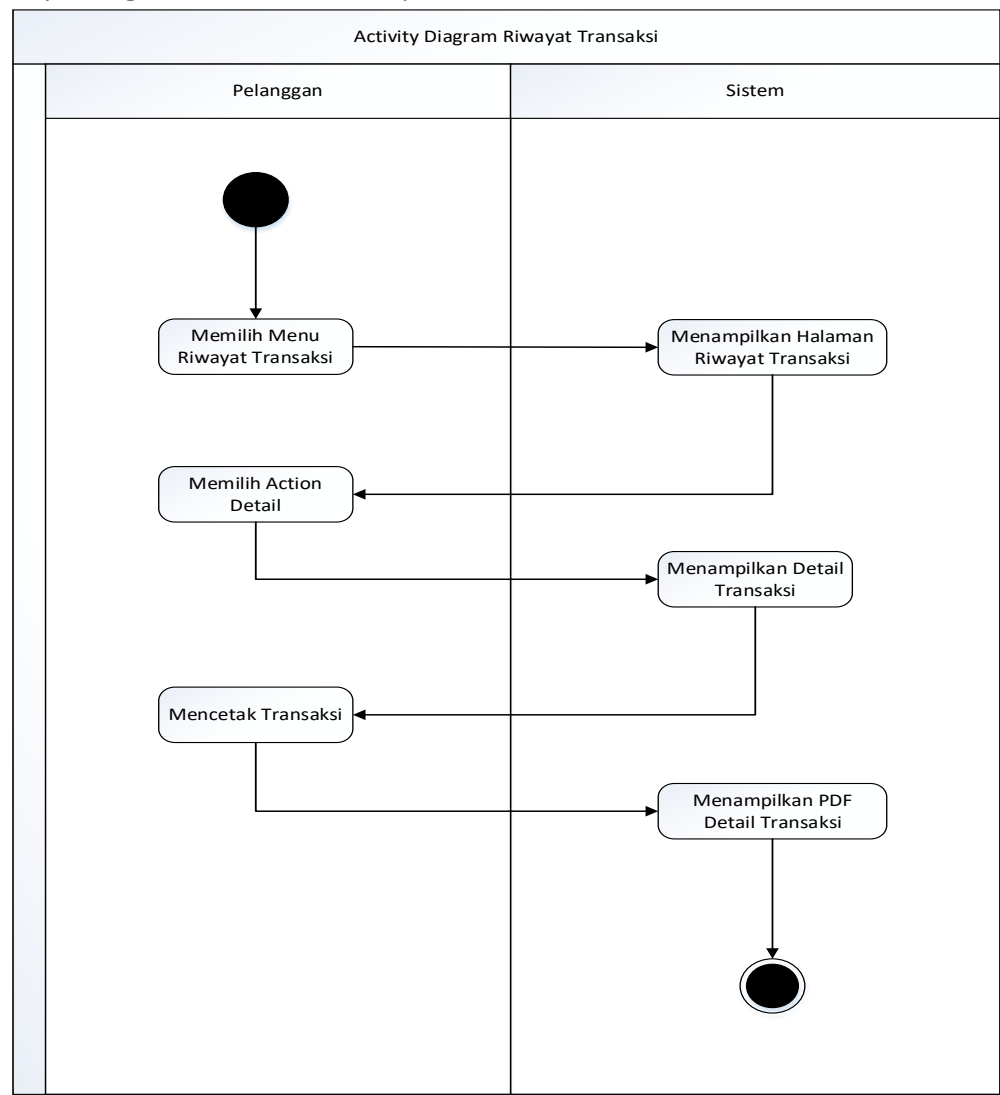

Gambar 4. Activity Diagram Meliat Riwayat Transaksi

Berikut adalah penjelasan activity diagram melihat riwayat transaksi:

1. Pelanggan mengklik menu riwayat transaksi.

2. Sistem akan menampilkan halaman riwayat transaksi.

3. Pelanggan memilih action detail.

4. Sistem akan menampilkan halaman detail transaksi. 


\section{JournalofInformation Systems andInformatics}

Vol. 2, No. 2, September 2020

p-ISSN: 2656-5935 http://journal-isi.org/index.php/isi

e-ISSN: 2656-4882

5. Pelanggan mencetak transaksi.

6. Sistem akan menampilkan pdf detail transaksi.

2. Activity Diagram Pembelian Barang

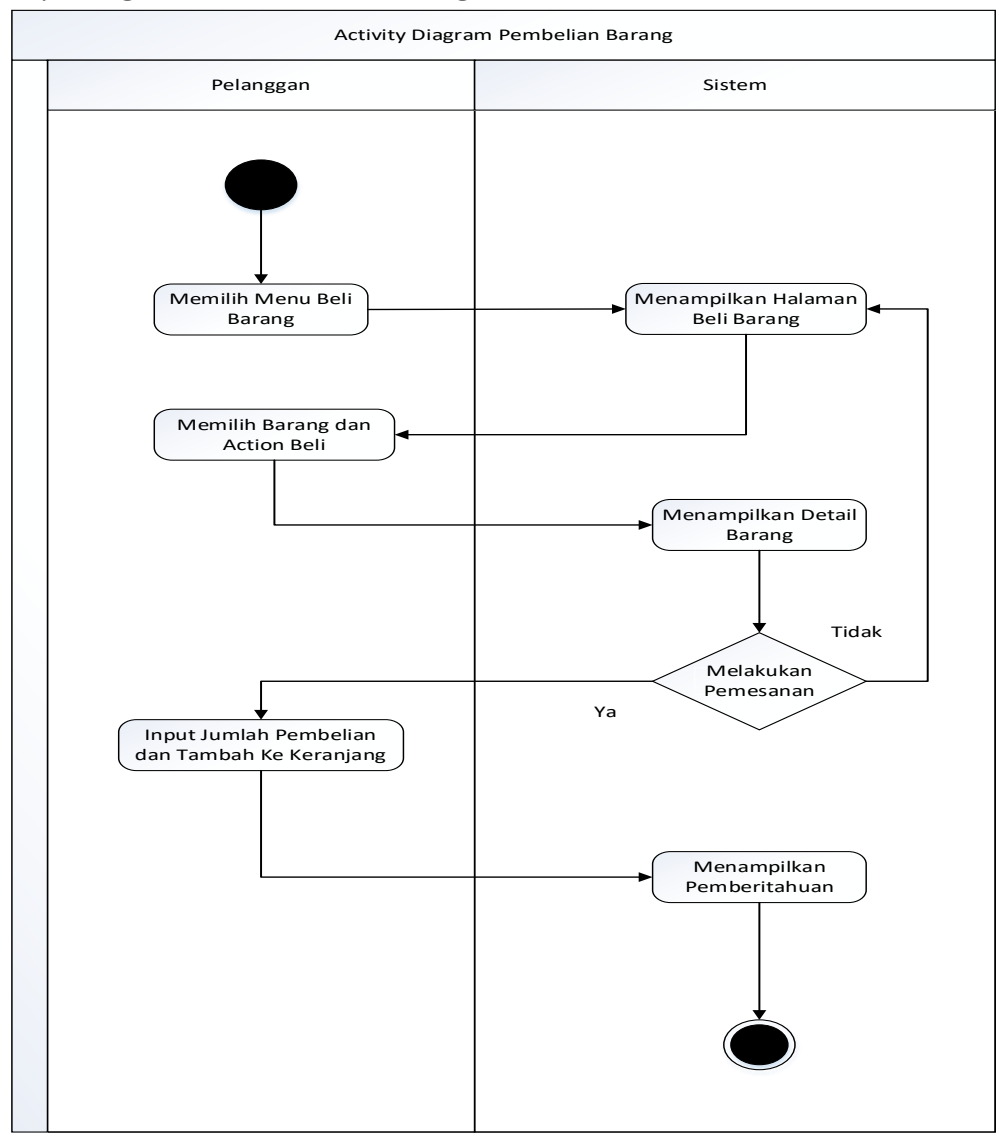

Gambar 5. Activity Diagram Pembelian Barang

Berikut adalah penjelasan activity diagram melakukan pembelian barang:

1. Pelanggan mengklik menu beli barang.

2. Sistem akan menampilkan halaman beli barang.

3. Pelanggan memilih barang dan mengklik action beli.

4. Sistem akan menampilkan halaman detail barang.

5. Pelanggan menginput jumlah pembelian, kemudian mengklik tambah ke keranjang. 


\section{JournalofInformation Systems andInformatics}

Vol. 2, No. 2, September 2020

p-ISSN: 2656-5935

http://journal-isi.org/index.php/isi

e-ISSN: 2656-4882

6. Sistem akan menampilkan pemberitahuan.

3. Activity Diagram Mengelola Keranjang Belanja

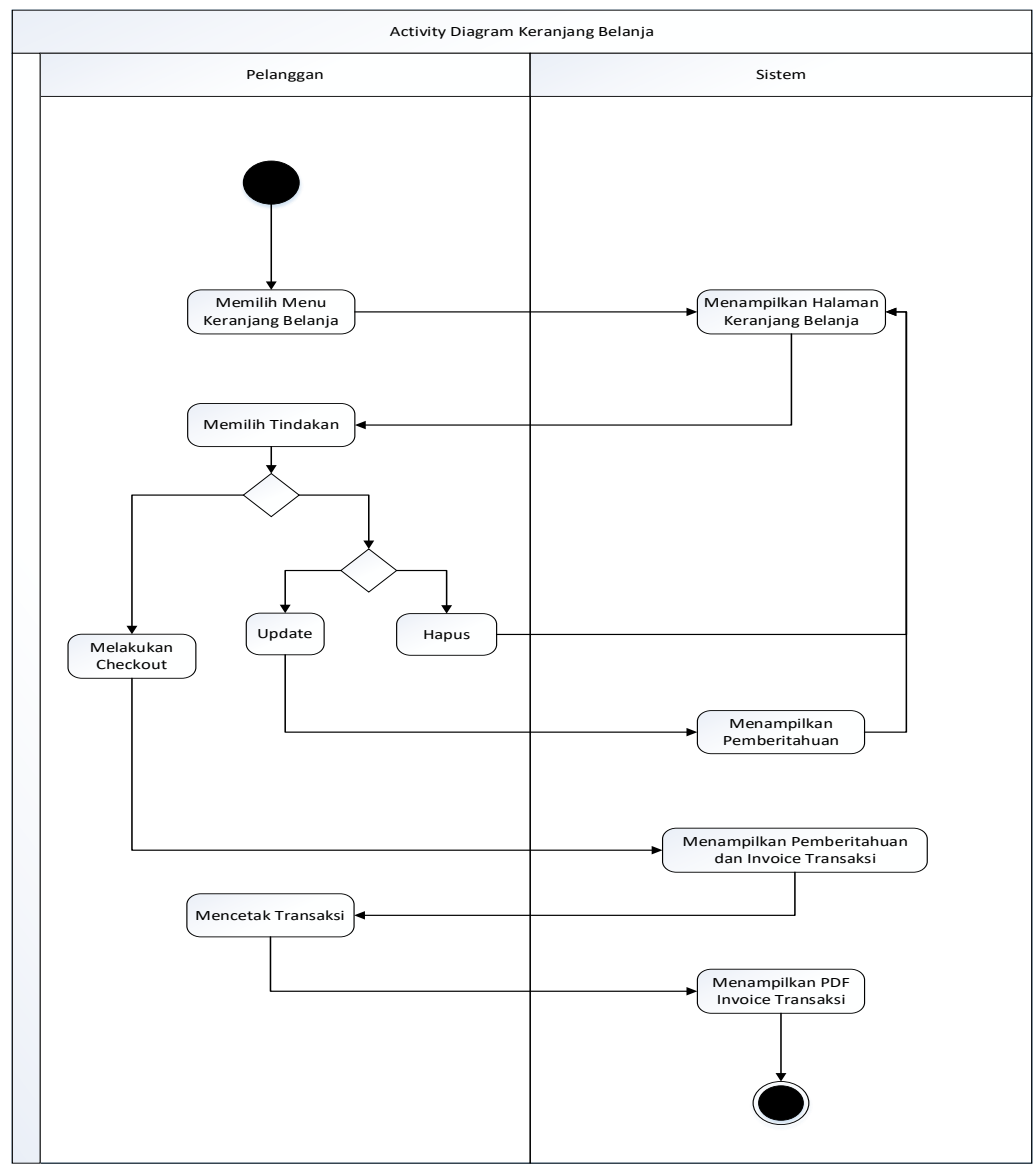

Gambar 6. Activity Diagram Mengelola Keranjang Belanja

Berikut adalah penjelasan activity diagram mengelola keranjang belanja:

1. Pelanggan mengklik menu keranjang belanja.

2. Sistem akan menampilkan halaman keranjang belanja.

3. Pelanggan memilih tindakan melakukan checkout, update atau hapus.

4. Sistem akan menampilkan pemberitahuan dan invoice transaksi.

5. Pelanggan mencetak transaksi.

6. Sistem akan menampilkan pdf invoice transaksi. 


\section{JournalofInformation Systems andInformatics}

Vol. 2, No. 2, September 2020

p-ISSN: 2656-5935

http://journal-isi.org/index.php/isi

e-ISSN: 2656-4882

4. Activity Diagram Mengelola Data Barang

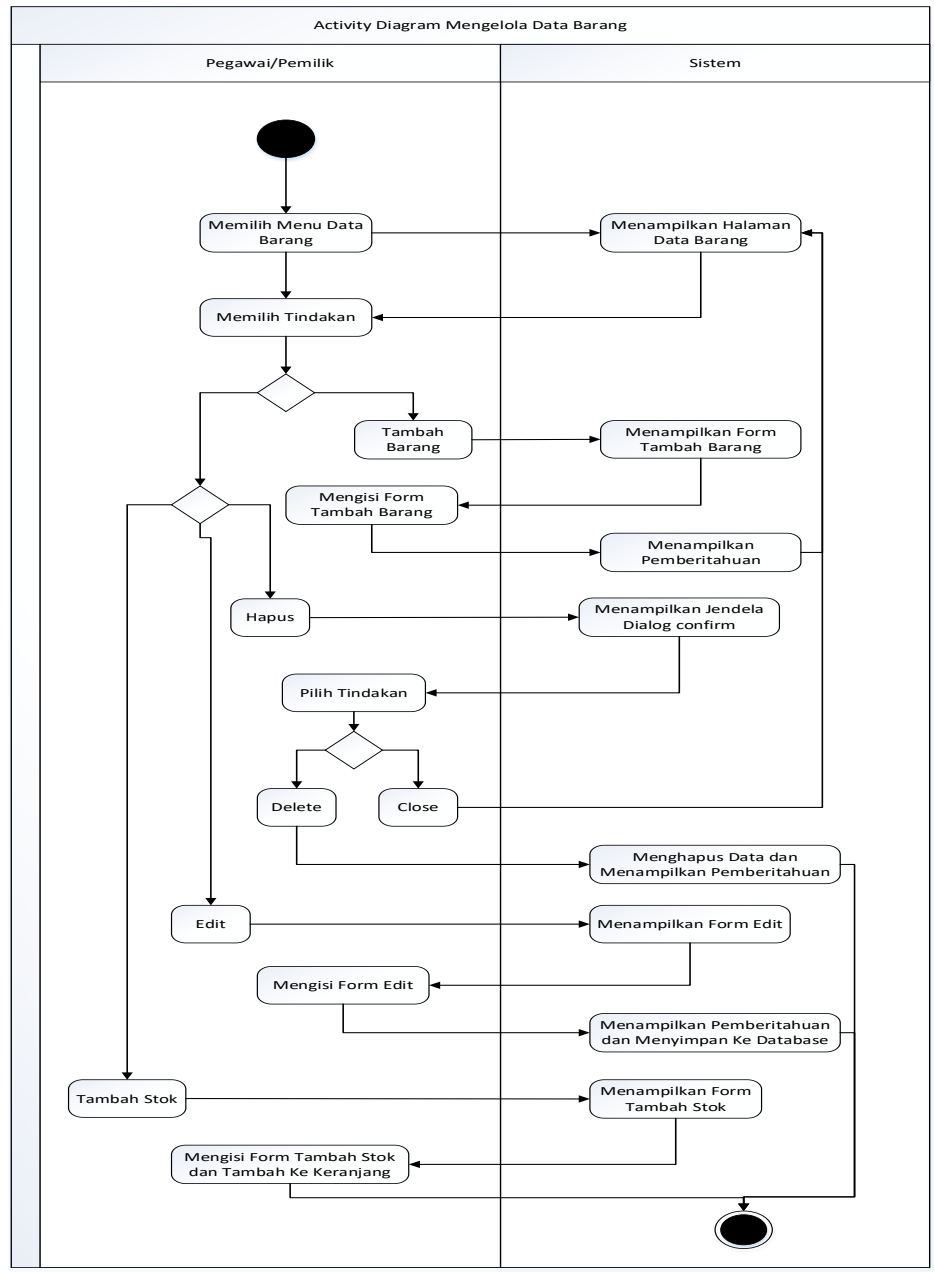

Gambar 7. Activity Diagram Mengelola Data Barang

Berikut adalah penjelasan activity diagram mengelola data barang:

1. Pegawai atau Pemilik mengklik menu data barang.

2. Sistem akan menampilkan halaman data barang.

3. Pegawai atau Pemilik memilih tindakan tambah barang, tambah stok, edit dan hapus data barang.

4. Sistem akan menampilkan halaman tambah barang, tambah stok, edit dan hapus data barang. 
JournalofInformation Systems andInformatics

Vol. 2, No. 2, September 2020

p-ISSN: 2656-5935 http://journal-isi.org/index.php/isi

e-ISSN: 2656-4882

\subsection{Desain Aplikasi}

1. Tampilan Menu Riwayat Transaksi

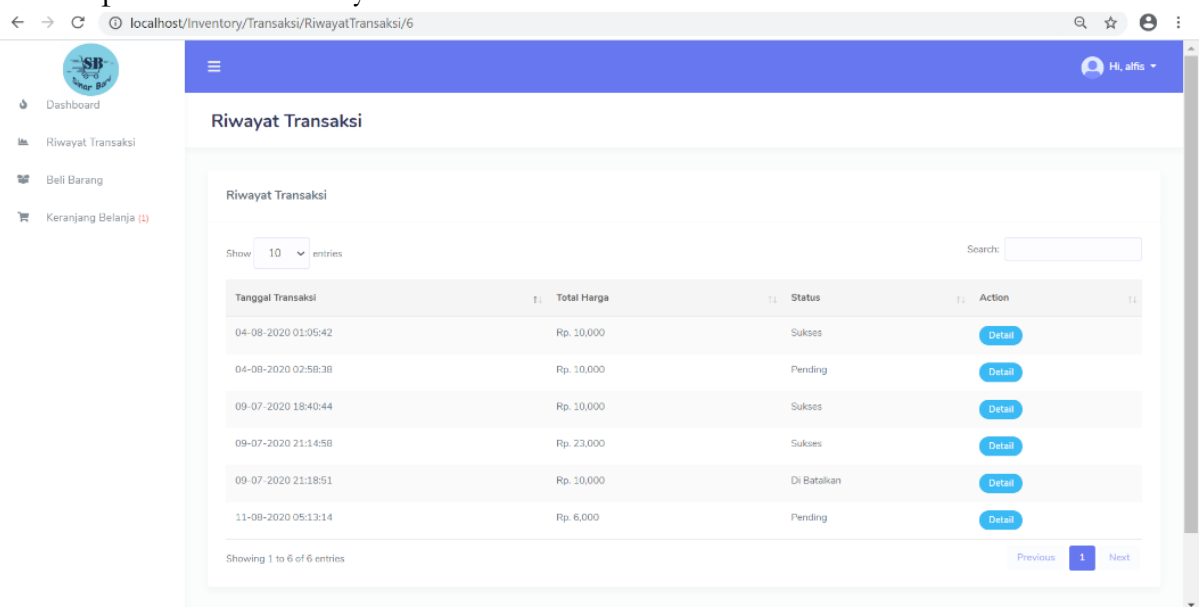

Gambar 8. Tampilan Menu Riwayat Transaksi

Pada menu riwayat transaksi terdapat aksi detail yaitu melihat data transaksi dan cetak invoice transaksi.

\section{Tampilan Menu Beli Barang}

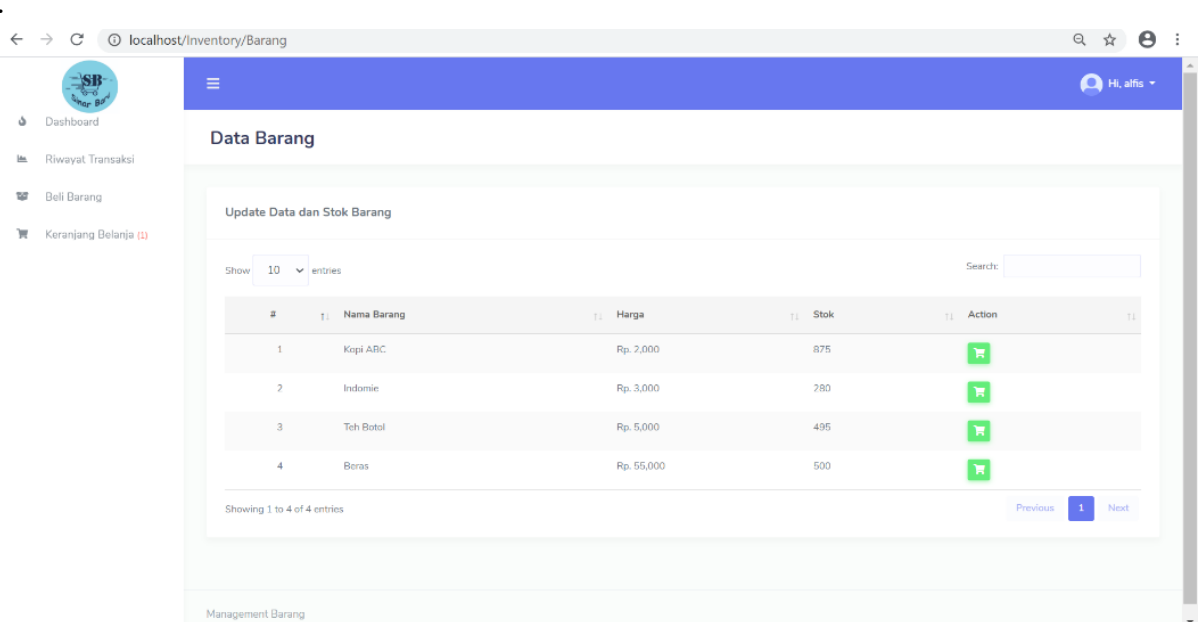

Gambar 9. Tampilan Menu Beli Barang

Pada menu beli barang terdapat aksi beli yaitu melakukan pembelian barang atau menambahkan ke keranjang belanja. 


\section{JournalofInformation Systems andInformatics}

Vol. 2, No. 2, September 2020

p-ISSN: 2656-5935

3. Tampilan Menu Keranjang Belanja

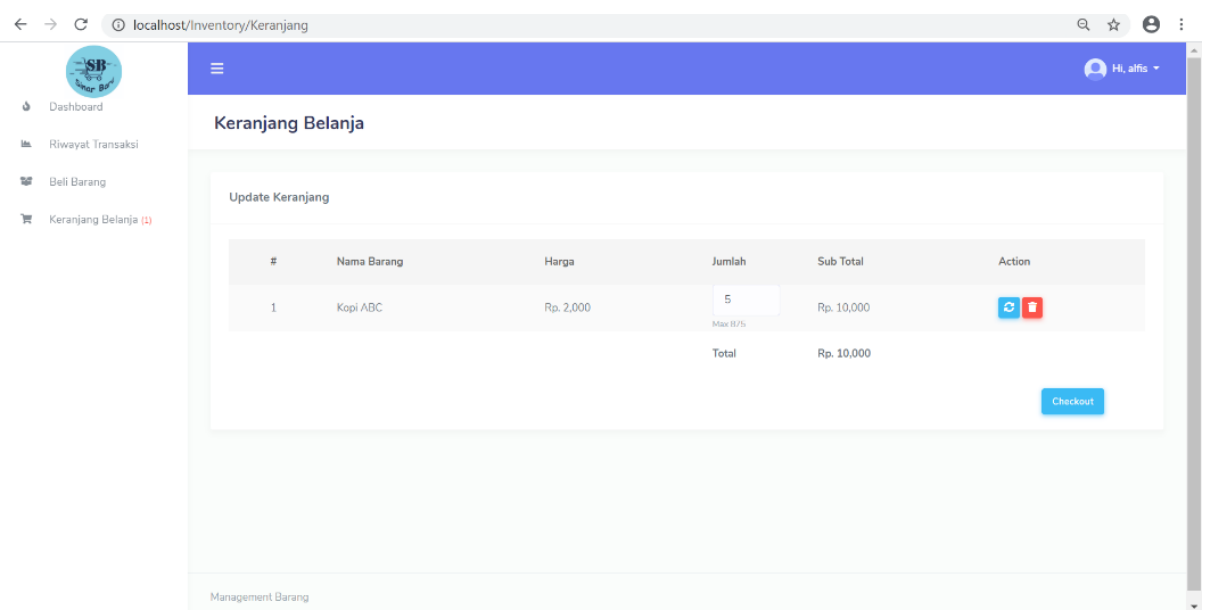

Gambar 10. Tampilan Menu Keranjang Belanja

Pada menu keranjang belanja terdapat aksi checkout yaitu melakukan pemesanan barang, akan berhasil jika admin sudah mengkonfirmasi pemesanan pembeliannya.

\section{Tampilan Menu Data Barang}

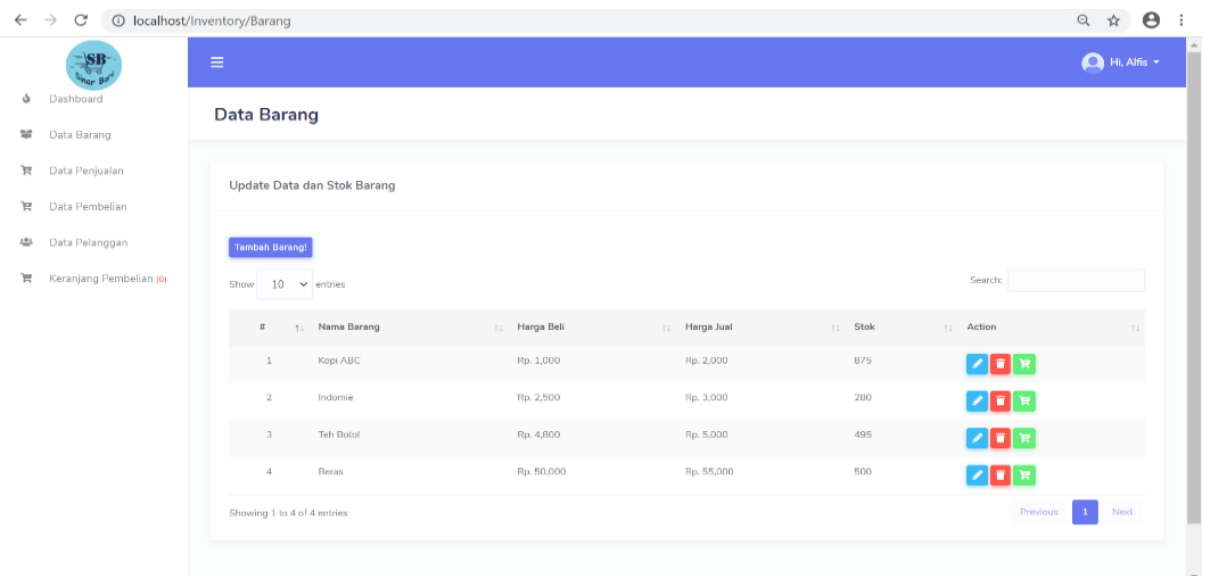

Gambar 11. Tampilan Menu Data Barang

Pada menu data barang terdapat berbagai aksi diantaranya yaitu tambah barang, edit barang, hapus barang dan tambah stok. 


\section{KESIMPULAN}

Dengan dibuatnya aplikasi ini agar mempermudah bagi agen sinar baru dalam hal penyimpanan data agar tidak terjadi kehilangan atau pencurian data oleh orang yang tidak bertanggung jawab dan juga dapat mengetahui ketersediaan barang yang tersedia pada toko, pembeli juga dapat membeli barang atau melihat ketersediaan barang yang dijual oleh agen melalui web yang tersedia agar lebih menghemat waktu atau effisiensi waktu.

\section{REFERENSI}

[1] M. P. Babar, M. Saitakela, P. Studi, S. Informasi, P. Studi, and S. Informasi, "Implementasi Customer Relationship Management ( Crm )," vol. 3, no. 1, pp. 1-10, 2019.

[2] C. Santika Putri, "Rancang Bangun Aplikasi Berbasis Web Persediaan Barang Di Toko 'Agen Snack," J. Manaj. Inform., vol. 6, no. 1, 2016.

[3] A. Anthony, A. R. Tanaamah, and A. F. Wijaya, "Analisis Dan Perancangan Sistem Informasi Penjualan Berdasarkan Stok Gudang Berbasis Client Server (Studi Kasus Toko Grosir 'Restu Anda')," J. Teknol. Inf. dan Ilmu Komput., vol. 4, no. 2, p. 136, 2017.

[4] A. Junaidi and C. Sumirat, "Aplikasi Persediaan Barang PT. CAD Solusindo Menggunakan Metode Waterfall," J. Sisfokom (Sistem Inf. dan Komputer), vol. 7, no. 1, p. 28, 2018.

[5] Fendi Nurcahyono, "Pembangunan Aplikasi Penjualan Dan Stok Barang Pada Toko Nuansa Elektronik Pacitan," Sentra Penelit. Eng. dan Edukasi, vol. 4, no. 3, pp. 15-19, 2012.

[6] S. Fauziah and Ratnawati, "Penerapan Metode FIFO Pada Sistem Informasi Persediaan Barang," J. Tek. Komput., vol. 4, no. 1, pp. 98-108, 2018.

[7] A. R. Ramadhani, H. Bunyamin, and L. Fitriani, "Perancangan Aplikasi Persediaan Barang dan Transaksi Penjualan Barang di Alya Store," J. Algoritm., vol. 13, no. 2, pp. 284-390, 2017.

[8] E. B. Prasetya, "Pembuatan Aplikasi Car Storage Dengan Menggunakan Metode Fifo (First in First Out ) Berbasis Web," Elektum, vol. 14, no. 1, p. $45,2017$.

[9] T. S. Jaya, "Pengujian Aplikasi dengan Metode Blackbox Testing Boundary Value Analysis (Studi Kasus: Kantor Digital Politeknik Negeri Lampung)," J. Inform. Pengemb. IT, vol. 3, no. 2, pp. 45-46, 2018.

[10] A. Fadillah and A. Ratnasari, "Sistem Informasi Penjualan Dan Manajemen Reimburse Pada Perusahaan Distribusi Berbasis Web (Studi Kasus: Pt. Karyatama Maju Berjaya)," J. Cendikia, vol. XVIII, pp. 298302, 2019.

[11] Y. P. W. Simaremare, A. Pribadi, S. Radityo, and P. Wibowo, 


\section{JournalofInformation Systems andInformatics}

Vol. 2, No. 2, September 2020

p-ISSN: 2656-5935 http://journal-isi.org/index.php/isi

e-ISSN: 2656-4882

"Perancangan dan Pembuatan Aplikasi Manajemen Publikasi Ilmiah Berbasis Online pada Jurnal SISFO," J. Tek. ITS, vol. 2, no. 3, pp. 470475, 2013. 